\title{
Incidence of bacterial and viral enteric pathogens in children with gastroenteritis over a one year-period, in Attica, Greece
}

Stylianos Chatzipanagiotou - Maria Economou - Constantina Papavasileiou • Anastassios Ioannidis · Vassiliki Ioannidou - Eleni Papavasileiou •

Aliki Voyatzi $\cdot$ Chryssoula Nicolaou

Published online: 20 December 2007

(C) Springer Science+Business Media B.V. 2007

Erratum to: Eur J Epidemiol (2006) 21:613-614

DOI: $10.1007 / \mathrm{s} 10654-006-9040-y$

The authors of this article have been incorrectly listed. The correct authors' names are listed above and below.

Springer wishes to apologise for any inconvenience caused.

The online version of the original article can be found under doi: 10.1007/s10654-006-9040-y.

S. Chatzipanagiotou $(\bowtie) \cdot M$. Economou - A. Ioannidis .

V. Ioannidou $\cdot$ C. Nicolaou

Department of Clinical Microbiology, Aeginition Hospital,

Athens Medical School, Athens, Greece

e-mail: schatzi@med.uoa.gr

C. Papavasileiou · E. Papavasileiou · A. Voyatzi

Department of Clinical Microbiology, Penteli Children Hospital,

Athens, Greece

S. Chatzipanagiotou

Department of Biopathology and Clinical Microbiology,

Aeginition Hospital, Athens Medical School,

Vass. Sophias av. 72-74, Athens 11528, Greece 